\title{
Study of the Efficiency of Two Antipyrenes for the Creation of Fireproof Polymeric Composite Materials
}

\author{
Sergey Barbot'ko' ${ }^{1}$, Mikhail Bochenkov ${ }^{1}$, Oleg Volniy ${ }^{1}$, Oleg Korobeinichev ${ }^{2}$, Andrei \\ Shmakov $^{2}$, Andrei Sivenkov ${ }^{3}$, and Anastasiia Babikova** \\ ${ }^{1}$ Federal State Unitary Enterprise «ALL-RUSSIAN SCIENTIFIC RESEARCH INSTITUTE OF \\ AVIATION MATERIALS», 105005, Radio st., 17, Moscow, Russia \\ ${ }^{2}$ Voevodsky Institute of Chemical Kinetics and Combustion, 630090, Institutskaya 3, Novosibirsk, \\ Russia \\ ${ }^{3}$ Academy of the State Fire Service of Emercom of Russia, 129366, Boris Galushkin st, 4, Moscow, \\ Russia \\ ${ }^{4}$ Peter the Great St. Petersburg Polytechnic University, 195521 Polytechnicheskaya, 29, Saint- \\ Petersburg, Russia
}

\begin{abstract}
Most of polymeric materials, when exposed to high temperatures, heat flows or an open flame, are capable of exothermic oxidation reactions - combustion. That is why polymeric materials are fire hazardous. The studies on creating a non-flammable polymer materials are crucial, as such products can make our everyday life a lot more safe. Studies have been carried out to assess the effectiveness of the action of two types of fire retardants (graphene and an organic phosphorus-containing compound DOPO-THPO), introduced into an epoxy resin. Evaluation of the effectiveness of the fire-retardant action was carried out by the methods of oxygen index (OI) and flammability according to UL 94. For the investigated compositions, it was found that there is no direct correlation between the value of the oxygen index and the ability of the samples to maintain self-combustion. For these compositions, the total duration of residual combustion in vertical tests and the speed of flame propagation in horizontal tests are naturally correlated. It was found that if the total duration of combustion of five samples during vertical tests is 500 seconds or less, then these compositions during horizontal tests will fade, that is, formally, their flame propagation speed will be equal to zero.
\end{abstract}

\section{Introduction}

In the modern world, one of the main trends is the increasing use of polymeric materials synthetic polymeric materials are gradually replacing metal alloys and natural materials [15]. This happens in all industries: in construction, transport, mechanical engineering, in everyday life, as they provide a higher level of properties [6-13].

\footnotetext{
*Corresponding author: anastasiia_babikova@mail.ru
} 
However, the overwhelming majority of polymeric materials, when exposed to high temperatures, heat flows or an open flame, are capable of exothermic oxidation reactions combustion - while heat, smoke and toxic substances are being released. That is why polymeric materials are fire hazardous $[12,14]$.

One of the ways to reduce the fire hazard of polymeric materials is the introduction of fire retardants into their composition [15-17]. However, the most popular flame retardants themselves often pose a hazard, since they form toxic substances when heated, or contribute to their formation during the thermal destruction of the polymer $[16,18]$. Therefore, recently the efforts of materials scientists and chemists have been directed towards the search, synthesis and implementation of new, safest, so-called «green» fire retardants [16].

Some of the safest fire retardants are fire retardants operating in the condensed phase. Examples of such flame retardants are organic phosphorus-containing flame retardants and nano-sized flame retardants.

The effectiveness of the action of organophosphorus fire retardants has long been known $[16,17]$, but many previously using fire retardants of this type cannot be synthesized due to the restrictions on the production of precursors imposed by the action of the Convention «On the prohibition of the development, stockpiling and use of chemical weapons and their destruction» $[19,20]$. Therefore, it is necessary to search for new organophosphorus compounds.

Most nanoscale flame retardants are extremely expensive, with nanoscale soot and graphite variants (intumescent and intercalated graphite, graphene) being one of the possible exceptions.

The most widely used engineering polymer materials are composites based on epoxy and polyester resins. These resins, along with high physical and mechanical characteristics of strength, have a satisfactory price level. Therefore, it is most expedient to conduct research on the search for new promising fire retardants capable of providing the required level of fire safety for polymer composite materials on one of these types of binders.

Research on the effectiveness of two types of fire retardants for epoxy binder was carried out under the grant of the Russian Science Foundation 20-19-00295 «Development of reinforced polymeric materials of low flammability, promising for use in the aviation industry, based on experimental research and computer modeling». The work was carried out within the framework of the implementation of a complex scientific problem 2.2. «Qualification and research of materials» of strategic direction 2. «Fundamental-oriented research, qualification of materials and non-destructive testing» («Strategic directions for the development of materials and technologies for their processing for the period up to 2030») [21].

\section{Materials and methods}

The studies presented in this work were aimed at assessing the effectiveness of two types of fire retardants: organophosphorus compounds and graphene.

The DOPO-THPO organophosphorus fire retardant is a new, low phosphorus, halogen free fire retardant. The fire retardant was developed and synthesized by the State Leading Laboratory of Fire Science of the University of Science and Technology of China and provided for this work by Professor Yuan $\mathrm{Hu}$. The synthesis method and chemical structure of the fire retardant are described in [22].

Graphene was manufactured by RUSGRAFEN LLC [23].

Epoxy resin ED 22, cured by TETA, was chosen as the polymer binder.

Samples containing graphene and DOPO-THPO were prepared according to the procedures described in [22, 24-26]. 
8 variants of compositions were made containing two types of fire retardants in different concentrations:

1. The original cured composition without fire retardants;

2. Composition containing $2 \%$ graphene;

3. Composition containing $4 \%$ graphene;

4. Composition containing $2 \%$ DOPO-THPO;

5. Composition containing 4\% DOPO-THPO;

6. Composition containing $1 \%$ graphene $+3 \%$ DOPO-THPO;

7. Composition containing $2 \%$ graphene $+2 \%$ DOPO-THPO;

8. Composition containing 3\% graphene $+1 \%$ DOPO-THPO.

Fire safety requirements are reflected in regulatory documents related to the construction industry and various types of transport [27-31]. The methods used to assess the fire hazard of the investigated materials vary greatly depending on the field of application $[32,33]$. In this regard, at the first stage of research, it was decided to conduct a preliminary assessment by the oxygen index method (GOST 12.1.044 89 p.4.14, GOST 21793 76, ASTM D2863, ISO 4589 2) and combustion resistance (GOST 28157-2018, UL 94).

In accordance with the requirements of the normative documentation for test methods, samples of appropriate sizes were made. When testing by the oxygen index method, the minimum oxygen concentration (OI) is determined, which ensures long-term independent candle-like combustion (from top to bottom) of the sample. Tests according to the GOST 28157-2018 (UL 94) method were carried out with two orientations of the sample: vertically - burning the sample from bottom to top and horizontally - determining the flame propagation velocity over a horizontally located sample.

\section{Results and discussion}

The results obtained using the abovementioned methods are presented in tables 1-3.

Table 1. Results of oxygen index tests

\begin{tabular}{|c|c|}
\hline Type and amount of fire retardant & Oxygen index, $\%$ \\
\hline No fire retardant & 21 \\
\hline Graphene $-2 \%$ & 26 \\
\hline Graphene $-4 \%$ & 27 \\
\hline DOPO-THPO $-2 \%$ & 22 \\
\hline DOPO-THPO $-4 \%$ & 23 \\
\hline Graphene $-1 \%+$ DOPO-THPO - 3\% & 25 \\
\hline Graphene $-2 \%+$ DOPO-THPO $-2 \%$ & 26 \\
\hline Graphene $-3 \%+$ DOPO-THPO $-1 \%$ & 28 \\
\hline
\end{tabular}

A detailed description of the samples, testing procedures by the oxygen index method and its results are provided in [26].

Table 2. Test results according to GOST 28157-2018 (UL 94) - vertical method

\begin{tabular}{|c|c|c|c|c|}
\hline Composition & $\begin{array}{c}\text { Burnout } \\
\text { length, mm }\end{array}$ & $\begin{array}{c}\text { Total burning } \\
\text { time of five } \\
\text { samples, } \mathbf{s}\end{array}$ & $\begin{array}{c}\text { The presence of } \\
\text { burning droplets that } \\
\text { ignite cotton wool }\end{array}$ & Definition \\
\hline No fire retardant & Total & 1051 & Precense detected & $\begin{array}{c}\text { Worse than } \\
\text { PV-2 (V-2) }\end{array}$ \\
\hline Graphene $-2 \%$ & Total & 849 & Precense detected & $\begin{array}{c}\text { Worse than } \\
\text { PV-2(V-2) }\end{array}$ \\
\hline
\end{tabular}




\begin{tabular}{|c|c|c|c|c|}
\hline Graphene $-4 \%$ & Total & 621 & Precense detected & $\begin{array}{c}\text { Worse than } \\
\text { PV-2 (V-2) }\end{array}$ \\
\hline DOPO-THPO $-2 \%$ & Total & 487 & Precense detected & $\begin{array}{c}\text { Worse than } \\
\text { PV-2 (V-2) }\end{array}$ \\
\hline DOPO-THPO $-4 \%$ & Total & 505 & Precense detected & $\begin{array}{c}\text { Worse than } \\
\text { PV-2 (V-2) }\end{array}$ \\
\hline $\begin{array}{c}\text { Graphene }-1 \%+ \\
\text { DOPO-THPO }-3 \%\end{array}$ & Total & 511 & Precense detected & $\begin{array}{c}\text { Worse than } \\
\text { PV-2 (V-2) }\end{array}$ \\
\hline $\begin{array}{c}\text { Graphene }-2 \%+ \\
\text { DOPO-THPO }-2 \%\end{array}$ & Total & 441 & Precense detected & $\begin{array}{c}\text { Worse than } \\
\text { PV-2 (V-2) }\end{array}$ \\
\hline $\begin{array}{c}\text { Graphene }-3 \%+ \\
\text { DOPO-THPO }-1 \%\end{array}$ & Total & 412 & Precense detected & $\begin{array}{c}\text { Worse than } \\
\text { PV-2 (V-2) }\end{array}$ \\
\hline
\end{tabular}

Table 3. Test results according to GOST 28157-2018 (UL 94) - horizontal method

\begin{tabular}{|c|c|c|c|}
\hline Composition & $\begin{array}{c}\text { Average speed of flame } \\
\text { propagation, mm / min }\end{array}$ & Note & Definition \\
\hline No fire retardant & 26,3 & Burned out to the clip & $\begin{array}{c}\text { Low } \\
\text { flammable }\end{array}$ \\
\hline Graphene $-2 \%$ & 24,2 & Burned out to the clip & $\begin{array}{c}\text { Low } \\
\text { flammable }\end{array}$ \\
\hline Graphene $-4 \%$ & 21,9 & Burned out to the clip & $\begin{array}{c}\text { Low } \\
\text { flammable }\end{array}$ \\
\hline DOPO-THPO $-2 \%$ & 0 & $\begin{array}{c}\text { Didn't burn out to the } \\
\text { 2nd mark }\end{array}$ & $\begin{array}{c}\text { Low } \\
\text { flammable }\end{array}$ \\
\hline DOPO-THPO $-4 \%$ & 0 & $\begin{array}{c}\text { Didn't burn out to the } \\
\text { 2nd mark }\end{array}$ & $\begin{array}{c}\text { Low } \\
\text { flammable }\end{array}$ \\
\hline $\begin{array}{c}\text { Graphene }-1 \%+ \\
\text { DOPO-THPO }-3 \%\end{array}$ & 0 & $\begin{array}{c}\text { Didn't burn out to the } \\
\text { 2nd mark }\end{array}$ & $\begin{array}{c}\text { Low } \\
\text { flammable }\end{array}$ \\
\hline $\begin{array}{c}\text { Graphene }-2 \%+ \\
\text { DOPO-THPO }-2 \%\end{array}$ & 0 & $\begin{array}{c}\text { Didn't burn out to the } \\
\text { 2nd mark }\end{array}$ & $\begin{array}{c}\text { Low } \\
\text { flammable }\end{array}$ \\
\hline $\begin{array}{c}\text { Graphene }-3 \%+ \\
\text { DOPO-THPO }-1 \%\end{array}$ & $\begin{array}{c}\text { Didn't burn out to the } \\
\text { 2nd mark }\end{array}$ & $\begin{array}{c}\text { Low } \\
\text { flammable }\end{array}$ \\
\hline
\end{tabular}

A detailed description of the samples, test procedures, requirements and permissible values according to GOST 28157-2018 (UL 94), and also the results, are provided in [34].

By varying the composition and content of fire retardants, it was possible to obtain compositions having an oxygen index of $26-28 \%$. It is usually believed that when the OI is equal to or more than $27 \%$, such materials will self-extinguish when ignited from below. However, as can be seen from table 2, samples of all compositions when tested vertically and fired from below had a long residual combustion and spread the flame along the entire length. In $[22,25]$, the authors managed to achieve for samples of categories PV 0 (V 0), however, in their case, an epoxy resin was used, which initially had a higher oxygen index $(26 \%$, instead of $22 \%$ in our case).

When tested by the vertical method in accordance with GOST 28157-2018 (UL 94), all samples burned to their entire free length and there was only a difference in the total duration of residual combustion. However, in this case, a decrease in the duration of the residual combustion does not allow us to unambiguously characterize the decrease in the combustion ability of the composition, since a decrease in the combustion time may indicate both a lower combustion ability, and vice versa, a more intense combustion (the same sample burns in a shorter time).

Comparison of the value of the oxygen index and the total duration of combustion when tested by the vertical method according to GOST 28157-2018 (UL 94) is shown in Fig. 1. 


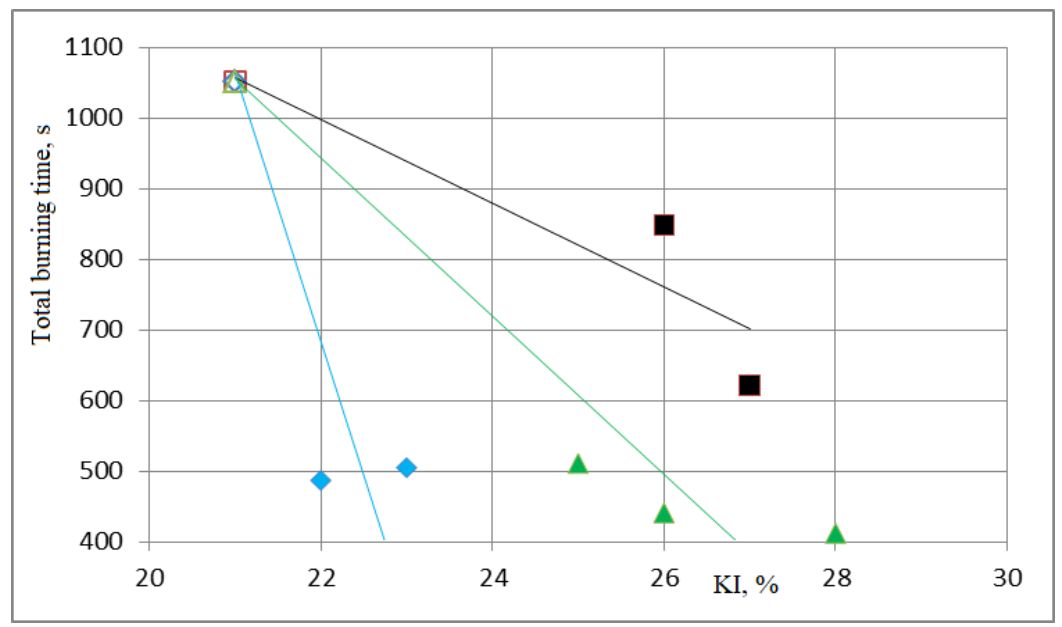

Fig. 1. Comparison of the values of the oxygen index (horizontal axis) and the total duration of residual combustion (ertical axis) when tested in the vertical position of the samples in accordance with GOST 28157-2018 (UL 94). Transparent marker - original composition, black marker - graphene, blue marker - DOPO-THPO, green marker - graphene + DOPO-THPO.

From the analysis of the data in Fig. 1 it can be seen that there is no direct relationship between the value of the oxygen index and the total duration of residual combustion. However, if we consider not the general population of data, but for individual options for the introduction of fire retardants, then we can see a natural decrease in the duration of combustion with an increase in the content of fire retardants (separate trend lines). From the analysis of the data presented, it follows that the most effective (both for increasing the oxygen index and reducing the duration of residual combustion) are compositions with the simultaneous introduction of two fire retardants.

Since, when tested by the vertical method according to GOST 28157-2018 (UL 94), the results of various compositions do not differ in the length of burnout, and there are differences only in the duration of residual combustion, tests were carried out with a horizontal version of the test method according to GOST 28157-2018 (UL 94).

Samples of the initial composition without fire retardants and with introduced graphene, when tested in the horizontal state, spread the flame along the entire length, while with an increase in the amount of the introduced fire retardant, the flame propagation rate naturally decreased. In the case of the introduction of an organophosphorus fire retardant, or the simultaneous introduction of two fire retardants, the flame on the samples when tested in a horizontal position faded, thus the speed of flame propagation over their surface is considered to be zero.

The general representation of the dependence of the flame propagation speed on the oxygen index is shown in Fig. 2 and is approximately similar to that shown in Fig. 2.

It can be seen that the ability to spread the flame does not depend on the value of the oxygen index, but is determined by the fire retardant material: the samples with the DOPOTHPO did not spread the flame over the horizontal surface at the OI values of 22 and 23, and the samples with introduced graphene at the index 27 - burned out to the full length.

If we compare the data on the duration of the residual combustion and the speed of flame propagation, a natural picture is obtained (Fig. 3): when the total duration of the residual combustion decreases to about 500 seconds, the flame propagation speed decreases to zero. 


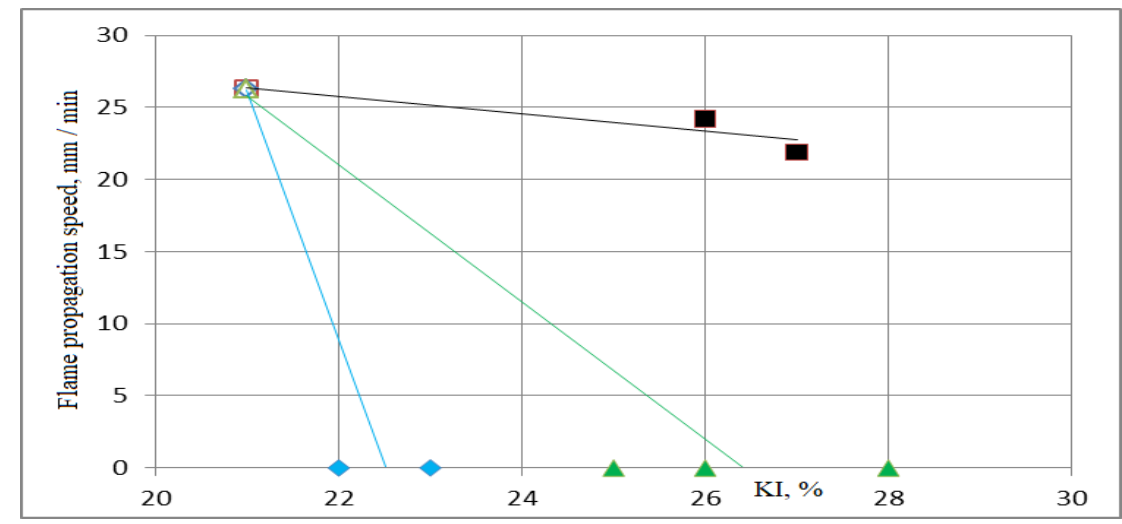

Fig. 2. Comparison of the values of the oxygen index (horizontal axis) and the flame propagation velocity (vertical axis) when tested in the horizontal position of the samples according to GOST 281572018 (UL 94). Transparent marker - original composition, black marker - graphene, blue marker DOPO-THPO, green marker - graphene + DOPO-THPO

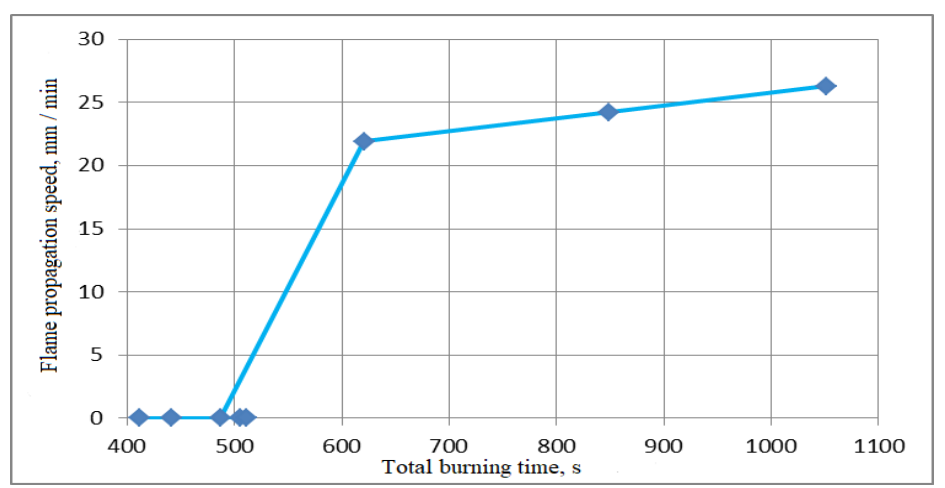

Fig. 3. Comparison of the value of the total duration of combustion during vertical testing (horizontal axis) and the speed of flame propagation during tests in the horizontal position of the samples (vertical axis) in accordance with GOST 281572018 (UL 94).

\section{Results and discussion}

Studies of two types of fire retardants - nanoscale (graphene) and organophosphate DOPOTHPO - have been carried out to assess their influence on the flammability parameters of epoxy compositions.

For the investigated compositions, it was found that there is no direct correlation between the value of the oxygen index and the ability of the samples to maintain self-combustion. For these compositions, the total duration of residual combustion in vertical tests and the speed of flame propagation in horizontal tests are naturally correlated. It was found that if the total duration of combustion of five samples during vertical tests is 500 seconds or less, then these compositions during horizontal tests will fade, that is, formally, their flame propagation speed will be equal to zero.

The paper was prepared within the framework of the work under the grant of the Russian Science Foundation 20-19-00295 «Development of reinforced polymeric materials of low flammability, promising for use in the aviation industry, based on experimental research and computer modeling». 


\section{References}

1. M. Chanda, Roy S.K., Industrial Polymers, Specialty Polymers, and Their Applications, CRC Press, USA, FL, 2009, 432 p. ISBN 978-1-4200-8058-2

2. Carbon Fiber Market - Global Forecast to 2026, MarketsandMarkets, 2016, $151 \mathrm{p}$.

3. E.N. Kablov, New generation materials and technologies for their digital processing, Herald of the Russian Academy of Sciences. 2020. Vol. 90. No. 2. P. 225-228.

4. E.N. Kablov, Marketing of material science, aircraft building and industry: Today and the future, General director of all-Russia scientific-research institute of aircraft materials (RIAM), 2017. № 5-6. P. 40-44.

5. E.N. Kablov, Materials are the basis of any business, Delovaya slava Rossii, 2013. №2. P.4-9.

6. J.K. Fink, Marine, Waterborne and Water-Resistant Polymers, Scrivener Publishing, USA, MA, 2016, 234 p. ISBN: 978-1-119-18486-7

7. Sustainable Composites for Aerospace Applications, Edited by M. Jawaid and M. Tharid, Woodhead Publishing, Elsevier, UK, USA (MA), 2018, 368 p. ISBN: 978-008-102138-5

8. L. Razdolsky, Probability Based High Temperature Engineering. Creep and Structural Fire Resistance, Springer International Publishing, Switzerland, 2017, 665 p. ISBN: 978-3-319-41909-1 DOI 10.1007/978-3-319-41909-1

9. 2012 International Building Code, International Code Council, USA, 2011, 732 p. ISBN: 978-1-60983-040-3

10. Aerospace Materials and Material Technologies. Volume 1: Aerospace Materials. Editors N.E. Prasad and R.J.H. Wanhill, Springer, Singapore, 2017, 594 p. ISBN $978-$ 981-10-2134-3, DOI 10.1007/978-981-10-2134-3

11. Composites forming technologies, Edited by A.C. Long, CRC Press, USA, Woodhead Publishing Limited, England, 2007, 345 p. ISBN 978-0-8493-9102-6

12. A.P. Mouritz, Gibson A.G. Fire Properties of Polymer Composite Materials, Springer, Netherlands, 2006, 398 p. ISBN-10 1-4020-5356-8

13. E.N. Kablov, Formation of Domestic Space Materials Science, Russian Foundation for Basic Research Journal, 2017. № 3. P. 97-105.

14. 2012 International Fire Code, International Code Council, USA, 2011, 548 p. ISBN: 978-1-60983-046-5

15. A.H. Buchanan, Abu A.K., Structural design for fire Safety. Second edition, Wiley USA, MA, 2017, 433 p. ISBN 9781118700402, DOI 10.1002/9781118700402

16. Polymer Green Flame Retardance. Edited by C.D. Papaspyrides and P. Kiliaris, Elsevier, Netherlands, UK, USA (MA), 2014, 943 p. ISBN: 978-0-44-53808-6

17. O.I. Tuzhikov, Hohlova T.V., Bondarenko S.N., Zotov S.B., Tuzhikov O.O., Rahmangulova N.I., Elastomers and low-flammability plastics, Volgograd, 2004, 230 p.

18. M. Green, Flame Retardant Chemicals: Technologies and Global Markets, BCC Research, USA (MA) 2015, 164 p. ISBN: 1-62296-080-7

19. Chemical Weapons Convention (CWC). URL: http://www.opcw.org/sites/default/files/documents/CWC/CWC_ru.pdf.

20. E.A. Serkova, Zastrogina O.B., Barbot'ko S.L., Investigation of the possibility of using new environmentally friendly organophosphorus fire retardants in the composition of 
binders for fireproof interior materials, Trudy VIAM 2019. №2 (74). P.24-34 . DOI:10.18577/2307-6046-2019-0-2-24-34. URL: http://www.viam-works.ru

21. E.N. Kablov, Innovative developments of FSUE "VIAM" SSC RF for the implementation of "Strategic directions for the development of materials and technologies for their processing for the period up to 2030", Aviation materials and technologies. 2015. №1 (34). P. 3-33. DOI:10.18577/2071-9140-2015-0-1-3-33.

22. J. Wang, Ma C., Wang P., Qiu S., Cai W., Hu Y., Ultra-low phosphorus loading to achieve the superior flame retardancy of epoxy resin, Polymer Degradation and Stability, 2018, №149, pp. 119-128. DOI:10.1016/j.polymdegradstab.2018.01.024

23. Graphene as microparticles in powder, RUSGRAPHEN https://rusgraphene.ru/productpage/graphene-powder

24. P. Wang, Fu X., Kan Y., Wang X., Hu Y., Two high-efficient DOPO-based phosphonamidate flame retardantsfor transparent epoxy resin, High Performance Polymers, 2018, March 8. DOI: 10.1177/0954008318762037 https: //journal.sagepub.com/doi/10.1177/0954008318762037

25. Wei Yan, Ming-Qiu Zhang, Jie Yu, Sheng-Qiang Nie, Dai-Qin Zhang, and Shu-Hao Qin, Synergistic Flame-retardant Effect of Epoxy Resin Combined with Phenethylbridged DOPO Derivative and Graphene Nanosheets, Chinese Journal of Polymer Science. 2019. №37. pp.79-88 https://doi.org/10.1007/s10118-019-2175-6

26. S.L. Barbot'ko, Bochenkov M.M., Volniy O.S., Korobeinichev O.P., Shmakov A.G., Evaluation of the effectiveness of fire retardants promising for the creation of new polymer composite materials intended for aviation technology, Trudy VIAM 2021. № 2 (96), 3. http://www.viam-works.ru DOI: 10.18577/2307-6046-2021-0-2-20-29

27. Federal Law of Russia №69. URL: https: //www.consultant.ru/document/cons_doc_LAW_5438

28. GOST R 55183-2012 Passenger cars on locomotive traction. Fire safety requirements, 2013, 16 p.

29. Aviation regulations. Part 25. Standards of airworthiness of aircraft of the transport category 2015. 288 p.

30. Airworthiness Standards: Transport Category Airplanes: Part 25, Electronic Code of Federal Regulation. Title 14: Aeronautic and Space. Chapter 1. Subchapter C. https://www.ecfr.gov/cgi-bin/textidx?SID=9091 f0ebbfbf1539cdb87015908ad369\&mc=true \&node=pt14.1.25\&rgn=div5

31. International Code for Application of Fire Test Procedures, 2010 (2010 FTR Code, IMO resolution MSC.307(88)), 2011, 560 p.

32. S.L. Barbot'ko, Volniy O.S., Kirienko O.A., Shurkova E.N., Assessment of fire safety of polymer materials for aviation purposes: analysis of the state, test methods, development prospects, methodological features, VIAM, 2018. $424 \mathrm{p}$.

33. Russian Government order. URL: https://docs.cntd.ru/document/902146883

34. S.L. Barbot'ko, Bochenkov M.M., Volniy O.S., Korobeinichev O.P., Shmakov A.G., Study of the effect of two types of fire retardants on the flammability of epoxy resin samples, Trudy VIAM 2021, 4 (98), p. 132-140. http://www.viam-works.ru DOI: 10.18577/2307-6046-2021-0-4-132-140 